\title{
Nutritional factors and visual function in premature infants
}

\author{
Victoria C. Jewell ${ }^{1 *}$, Christine A. Northrop-Clewes ${ }^{1}$, Richard Tubman ${ }^{2}$ and David I. Thurnham ${ }^{1}$ \\ ${ }^{1}$ Northern Ireland Centre for Diet and Health, University of Ulster, Coleraine BT52 1SA, UK \\ ${ }^{2}$ Neonatal Intensive Care Unit, Royal Maternity Hospital, Belfast BT12 6BB, UK
}

\begin{abstract}
Approximately 5-7 \% of all infants are born prematurely, and birth before 37 weeks is the most common cause of neonatal mortality, morbidity and long-term disability. Premature infants are poorly equipped for life outside the womb, and oxidant stress has been implicated in the aetiology of visual impairment in these infants, who are often exposed to increased $\mathrm{O}_{2}$ concentrations and high light intensity in neonatal units. The carotenoids lutein and zeaxanthin, which give the macular area of the eye its yellow colour, are located in the retinal pigment epithelium of the eye, and are believed to play a role in protecting it against oxidative and light damage. The macular pigments are of dietary origin, and green leafy vegetables are the primary source of lutein and zeaxanthin. Lutein is one of the five most common carotenoids found in the diet. There is current interest in the macular pigment in relation to age-related macular degeneration, but these pigments may also have a protective role in the retinal pigment epithelium of the newborn infant. Little information is available on blood lutein and zeaxanthin levels in neonates. Levels of lutein in human milk are two to three times higher than those of $\beta$-carotene, whereas their concentrations in the mothers' blood are approximately the same. Human milk is the main dietary source of lutein and zeaxanthin for infants until weaning occurs. The biochemical mechanisms which mediate the transport of the macular carotenoids into the eye are not known, but tubulin has been identified as the major carotenoid-binding protein, and may play a role in the physiology of the macula.
\end{abstract}

Prematurity: Lutein: Zeaxanthin: Macula

Evidence has accumulated over the past few decades concerning the antioxidant role of carotenoids, particularly in their potentially protective role in the development and course of chronic diseases, i.e. heart disease, cancer, asthma, diabetes and degenerative eye disease (Ford et al. 1999). Although it is still not clear how carotenoids function in these conditions, some recent work has suggested that carotenoids may stimulate the immune system (Hughes, 1999). However, lutein and zeaxanthin are two carotenoids which may have a direct effect on the metabolism and function in the eye. Macular disease in the elderly has been linked to inadequate dietary lutein through a low vegetable intake, and retinopathy of prematurity may have a similar aetiology. It is believed that retinopathy of prematurity may be initiated by oxidative damage caused by high levels of illumination and/or $\mathrm{O}_{2}$ in the hospital ward, and the vulnerability of the immature tissue. Lutein and zeaxanthin in the retinal pigment epithelium (RPE) absorb light and may have an antioxidant function, hence protecting the eyes of young infants from damage by illumination. However, there is little information on the carotenoid status of young infants (Jewell et al. 2000).

\section{Premature birth}

Premature birth is the most common cause of neonatal mortality, morbidity and long-term disability (Bonn, 1998). In the UK and Ireland 5-7 \% of infants are born prematurely (Gorman et al. 1996). Premature birth is internationally defined as any infant born before 37 weeks gestation (259 d). Term infants are those born between 37 and 41 weeks (259-293 d) or later (Gibson, 1982). Infants born weighing $<2500 \mathrm{~g}$ at birth are termed low birth weight (LBW), those weighing $<1500 \mathrm{~g}$ are termed very-low birth weight (VLBW) and those weighing $<1000 \mathrm{~g}$ are referred to as extremely-low birth weight (ELBW; World Health Organization, 1961). Survival rates of ELBW infants increased from $10-20 \%$ in the 1960s, to approximately $40-70 \%$ in the 1980s (Yu et al. 1986). Prematurity accounts for at least $75 \%$ of early infant deaths; however, the survival of those 
infants has improved greatly, and subsequently their quality of life has improved dramatically. Neonatal intensive care was developed in the late 1970s and has continued to evolve since then. Increased survival is due to improvements in treatment, environment and diet, yet potentially fatal conditions continue to occur in vulnerable infants, and these infants are at a high risk for visual and neurological impairment.

\section{Causes of premature birth}

A number of factors have been associated with premature birth, and these include healthcare risks, previous obstetric history, demographic risks and environmental and lifestyle risks. Multiple pregnancies, pre-eclampsia, bacterial vaginosis and sexually-transmitted disease are associated with premature birth (Main \& Hadley, 1988). Stress, low social class, smoking, excessive alcohol intake and drugs are also associated with premature birth. In addition, there is a higher risk of premature birth among women aged $\leq 19$ years and women aged $\geq 40$, those unmarried, and of a race other than white (Main \& Hadley, 1988).

\section{Neonatal mortality}

The survival rate for preterm infants has improved dramatically with advances in perinatal care, especially due to efforts to reduce neonatal respiratory distress syndrome. The mortality rate for infants born at 23-36 weeks in an Australian study from 1994-7 was approximately 5\% (Doyle et al. 1999). The causes of death included lethal congenital anomalies, complications of prematurity such as hyaline membrane disease, broncho-pulmonary dysplasia, intraventricular haemorrhage, cystic periventricular leucomalacia, pulmonary haemorrhage, necrotising enterocolitis, perinatal asphyxia, and sepsis. The mortality rate between 1994 and 1997 diminished rapidly in infants born at 23-28 weeks gestation (from $64.5 \%$ at 23 weeks to $4.0 \%$ at 28 weeks), then more slowly to reach $0.4 \%$ at 36 weeks. Lethal anomalies were the most common cause of death.

In England and Wales neonatal mortality rate declined by $20 \%$ during the last decade, largely due to a fall in deaths from congenital anomalies (Cartlidge et al. 1999). A nationwide study in England and Wales showed the incidence of survival of VLBW infants (Alberman \& Botting, 1991); the number of survivors weighing 500-999 g at birth increased by $50 \%$ between 1983 and 1985 , with a $30 \%$ overall increase in survivors weighing less than $1500 \mathrm{~g}$. Likewise in Ireland, Gorman et al. (1996) showed neonatal mortality in the 1990 s to be about $15 \%$. Lethal malformations accounted for $5 \%$. Survival rates increased greatly from $33 \%$ for infants weighing 501-750 g, to $94 \%$ for infants weighing 1001-1250 g. All infants weighing 1501-1750 g survived (Table 1).

An investigation by Cooke (1996) examined 1722 VLBW infants admitted over a 12-year period from 1982 to 1993. Over this period neonatal survival increased by $10 \%$, with a decrease in parenchymal cerebral haemorrhage and cerebral palsy rates in survivors. He attributed this increased survival to the greater use of antenatal steroid prophylaxis.

\section{Neonatal morbidity}

The long-term outcome of premature infants has been the focus of many investigations in recent years (Morris et al. 1999). Recent recommendations suggest that health status of premature infants is best described at 2 years of age (corrected for gestation; Bohin et al. 1999). This study used the (UK) Audit Commission (1993) recommendations for descriptions of later health status (Table 2; National Perinatal Epidemiology Unit, 1994). This scheme divides information on the child's health status into different body areas and indicates a 'level' which can be considered severely abnormal. It should be realised, however, that although a child may be declared 'intact' at 2 years of age, it does not mean that they have escaped 'unscathed'. They may have school problems and learning disabilities that do not appear until later, for example, at school age.

All studies show that mortality and morbidity are highest in the smallest and least-mature infants. Le Blanc et al. (1999) looked at the outcome of ELBW infants in Mississippi, USA. The follow-up was done at approximately 2 years, and included infants born between 1992 and 1996 in the University of Mississippi Medical Center, MS, USA. Infants were classified 'intact' if they were neither deaf nor blind and had no cerebral palsy, or were without any form of moderate or mild disability. Of the survivors born between 23 and 25 weeks $50 \%$ had some form of disability at follow-up.

Elder et al. (1999) looked at hospital admissions in the first year of life in VLBW infants in Western Australia, and showed a high rate of readmission (42\%). Chronic lung disease was found to be the predominant perinatal factor, necessitating both surgical and medical readmission, particularly in boys (54\% of those readmitted). The most common reason for surgical readmission was for hernia repair, and risk of hernia increased with decreasing gestational age, male gender, occurrence of severe hyaline membrane disease and development of chronic lung disease.

Table 1. Impairments in infants born prematurely (\%)

\begin{tabular}{|c|c|c|c|c|c|c|}
\hline Study & Subjects & Cerebral palsy & Developmental delay & Vision & Hearing & Epilepsy \\
\hline Bohin et al. (1999) & $\begin{array}{l}n 55 \\
<1500 \mathrm{~g} \text { at birth } \\
\leq 25 \text { weeks gestation }\end{array}$ & $16 \cdot 4$ & $30 \cdot 9$ & $1 \cdot 8$ & $9 \cdot 1$ & $7 \cdot 3$ \\
\hline Veen et al. (1991) & $\begin{array}{l}n 966 \\
<1500 \mathrm{~g} \text { at birth } \\
<25 \text { weeks gestation }\end{array}$ & $30 \cdot 6$ & $16 \cdot 1$ & $27 \cdot 7$ & $6 \cdot 2$ & * \\
\hline
\end{tabular}

\footnotetext{
* Data not available in the study.
} 
Table 2. Scheme for assessing the outcome of children who have received neonatal intensive care (Audit Commission, 1993)

\begin{tabular}{|c|c|}
\hline Type of impairment & Definition \\
\hline Cerebral palsy & $\begin{array}{l}\text { (a) Any neuromotor impairment, with } \\
\text { disability, due to a brain lesion; (b) unable } \\
\text { to walk, even with aids }\end{array}$ \\
\hline Developmental delay & $\begin{array}{l}\text { Developmental quotient on the Griffiths scale } \\
\text { of less than } 70 \text {, or }>2 \text { SD below the mean } \\
\text { for other similar clinical tests. Tests should } \\
\text { be corrected for gestational age }\end{array}$ \\
\hline Vision & $\begin{array}{l}\text { Significant impairment in both eyes (if } \\
\text { measurable, corrected binocular visual } \\
\text { acuity of } \leq 6 / 24 \text { ) }\end{array}$ \\
\hline Hearing & $\begin{array}{l}\text { Bilateral impairment requiring hearing aids } \\
\text { (hearing loss greater than } 60 \mathrm{~dB} \text { ) }\end{array}$ \\
\hline Growth & $\begin{array}{l}\text { A weight of }>2 \text { SD below the mean, a height } \\
\text { of }>2 \text { SD below the mean, a head } \\
\text { circumference of }>2 \text { SD below the mean }\end{array}$ \\
\hline Epilepsy & $\begin{array}{l}\text { A diagnosis of epilepsy and needing regular } \\
\text { medication }\end{array}$ \\
\hline $\begin{array}{l}\text { Other serious and } \\
\text { continuing } \\
\text { conditions }\end{array}$ & $\begin{array}{l}\text { To include continuous breathlessness, hydro- } \\
\text { cephalus that has required a shunt, stoma } \\
\text { and loss of a limb }\end{array}$ \\
\hline
\end{tabular}

The outcome of many LBW, VLBW and ELBW infants has improved immensely in recent years, and much of this improvement can be attributed to the management of respiratory diseases with which many of these infants are born. Due to the fact that these infants are born with underdeveloped lungs, many deaths are related to the severity of neonatal respiratory distress syndrome, or the associated complications and sequelae (Cartlidge et al. 1999). Major advances in this area have been made; clinical trials show that both pre-delivery corticosteroids and surfactant-replacement therapy reduce mortality from respiratory distress syndrome.

The developmental outcome in premature infants in relation to feeding was investigated by Morris et al. (1999). They found that respiratory factors influenced the time required to reach full enteral and nipple feedings, and infants able to tolerate enteral feedings at an earlier age had an increased chance of better mental developmental outcome at 24 months. The mechanism is unknown, but the results enforce the proposal that providing enteral nutrition is one of the most important treatments that can be given to premature infants.

\section{Antioxidants and oxidant stress}

Oxidant stress has been implicated in the ageing process and in a large number of important human diseases, including cancer, cardiovascular disease and stroke (Blanche et al. 1999; Table 3). The term 'reactive oxygen species' is a collective term which includes not only oxygen-centred free radicals, but also some non-radical derivatives such as $\mathrm{H}_{2} \mathrm{O}_{2}$ and $\mathrm{HOCl}$. Oxidative stress probably arises when damage arising from reactive oxygen species is not repaired rapidly enough. All the major classes of biomolecules are vulnerable to free radical damage. Free radicals cause strand
Table 3. Some examples of degenerative diseases which may be linked to oxidative damage in their aetiology (Hughes, 1999)

Disease

Macular degeneration

Cataract formation

Cancer

Cardiovascular disease and atherosclerosis

Stroke

breaks in DNA (Halliwell \& Aruoma, 1991), which potentially can lead to subsequent disrepair and tumour cell formation.

Premature and small-for-gestational age infants have a high risk of visual impairment. In particular, there is a high risk of retinopathy of prematurity, strabismus (Pennefather et al. 1999), significant refractive error and periventricular leucomalacia (Gorman et al. 1996) which can be associated with neurological dysfunction, i.e. optical atrophy and cortical blindness. Retinopathy of prematurity develops when the normal pattern of progressive blood vessel growth within the retina is disrupted following premature birth, leading to vascular proliferation haemorrhage and retinal degeneration. Oxidant stress has been implicated in the aetiology of these conditions. Infants are often exposed to potentially-damaging concentrations of $\mathrm{O}_{2}$ (due to their respiratory problems) and high light intensity in neonatal units.

Links have emerged between diets rich in antioxidant nutrients and a lower incidence of certain diseases (e.g. cancer, cardiovascular disease) and effects on immune function. It has been suggested that a boost to the body's immune system by antioxidants may in part account for this outcome (Hughes, 1999). It is probably crucial to attempt to maintain the balance between reactive oxygen species and antioxidants, ideally by dietary means rather than supplementation, from as early an age as possible in the population, to prolong, if not prevent, the onset of agerelated disorders (Hughes, 1999).

Many antioxidants and other micronutrients can be obtained from fruit and vegetables in the diet, including ascorbate (vitamin $\mathrm{C}$ ), $\alpha$-tocopherol, carotenoids and polyphenolic flavanoids. In addition, several micronutrients function as integral components within the endogenous antioxidant defences of the body (e.g. Se in the metalloenzyme glutathione peroxidase; Hughes, 1999).

A recent report gives an excellent example of the potential need to maintain adequate intakes of antioxidants in the middle years of life, in order to prevent accumulative damage caused by reactive oxygen species manifesting later in life. Jacques et al. (1997) examined the relationship between age-related lens opacities and vitamin $\mathrm{C}$ supplementation over a 10-12-year period in 247 women aged between 56 and 71 years, without cataract or diabetes. A 77 $\%$ lower prevalence of early lens opacities was associated with the use of vitamin $\mathrm{C}$ supplements for 10 years or more, and an $83 \%$ lower prevalence of moderate lens opacities, compared with women who did not use supplements. There was no evidence of a reduced prevalence of early lens 
opacities in women consuming supplements for less than 10 years, suggesting that long-term supplementation with vitamin $\mathrm{C}$ may substantially reduce the development of agerelated lens opacities.

\section{Lutein and zeaxanthin (the macular pigments)}

It is well known that the eye is sensitive to the effects of light, particularly blue light, and that antioxidants are important in its protection (Bernstein et al. 1997). The macular region of the eye at the centre of the retina is the region of highest visual discrimination and is particularly adversely affected by high light intensity, although all parts of the retina may be affected (Bernstein et al. 1997). The metabolic activity of the RPE in the eye is particularly high, as are the polyunsaturated fatty acid levels in retinal tissues. Such conditions will potentially increase the risk of oxidant damage to the RPE, an area exposed to oxidative insult from blue light. In particular the presence of sensitizers (e.g. drugs and chemicals, such as allopurinol or phenothiazines) may induce the production of oxidant species such as singlet oxygen or superoxide. Ascorbate is a powerful reducing substance with potent radical-scavenging properties (Thurnham, 1988). It has been shown to protect against these species and can be found in high concentrations in the vitreous humor (and aqueous humor and lens) of the eye. The lens also provides some protection against blue light, but this is not particularly effective in the young.

The distribution of the two carotenoids in the retina was studied by Bone et al. (1988). In the inner macula zeaxanthin is dominant, but moving away from the fovea the concentrations change, leading to lutein becoming the dominant component, with values for lutein:zeaxanthin of 2:1-3:1. Bone et al. (1988) and Sommerburg et al. (1999) also suggested that the distribution of the carotenoids may be associated with the distribution of the rods and cones.

Lutein and zeaxanthin are two yellow carotenoids that give the macular area of the eye its colour, and are selectively accumulated in this part of the eye. Lutein and zeaxanthin are specifically located in the RPE, and are believed to play a role in protecting it against oxidative and light damage (Bone et al. 1985). As they are the only carotenoids present in the macula lutea and retina, they are believed to exhibit specific biological functions (Bone et al. 1997). These carotenoids have been implicated in macular function and prevention of degeneration (Bone et al. 1988), and although current interest is mainly concerned with the role of lutein and zeaxanthin in relation to age-related macular degeneration, they may also be important as protective factors in the RPE of the newborn infant.

Protection may be offered by lutein and zeaxanthin in two ways; by absorbing blue light before it reaches sensitizers which initiate photochemical damage, and by the general ability of carotenoids to quench singlet oxygen and free radicals (Bone et al. 1997). Common findings in children with a history of retinopathy of prematurity are retinal thinning, with diffuse hypopigmentation and mottled pigmentation of the macula (Minicucci et al. 1999). These physical signs may indicate failure to accumulate, or loss of, lutein and zeaxanthin, and therefore any antioxidant effects they may have.
Studies in monkeys have shown that the macular pigments are of dietary origin, since those fed diets devoid of lutein and zeaxanthin failed to develop yellow pigmentation of the macular area (Malinow et al. 1980). Green leafy vegetables are the primary source of lutein and zeaxanthin. Lutein is widely distributed in green vegetables (it is a major chloroplast pigment and therefore present in all green leafy vegetables), and is one of the five most common carotenoids found in the diet. The concentration of zeaxanthin in the diet is generally very low, and it is found in significant amounts in few foods. Yellow maize is the richest source of dietary zeaxanthin, but is not consumed in large quantities in Western diets. Peppers and fruits such as peaches and oranges are also good sources (Sommerburg et al. 1998). There must be a highly-specific mechanism for incorporating lutein and zeaxanthin into the eye, since zeaxanthin is specifically located in the macular region and the total concentration of other carotenoids in the entire RPE is not more than $1 \%$. The biochemical mechanisms which mediate the uptake and stabilisation of the macular carotenoids are not known, but Bernstein et al. (1997) identified tubulin as the major carotenoid-binding protein. Investigations using tissue derived from the human macula (foveal tissue) showed that tubulin binds macular carotenoids, and this binding interaction may play a role in the physiology of the macula.

\section{Supplementation studies}

Landrum et al. (1997) investigated the effect of lutein supplementation on the macular pigment. They supplemented two subjects with $30 \mathrm{mg}$ lutein/d for $140 \mathrm{~d}$ and regularly measured macular pigment optical density using a heterochromatic flicker photometer. They observed that macular pigment optical density increased by $39 \%$ in subject $A$, and by $21 \%$ in subject $B$, and that serum lutein concentrations increased tenfold. At 40-50 d after supplementation ceased serum levels returned to baseline but macular pigment optical density did not. The increased macular pigment optical density was estimated to have produced a $30-40 \%$ reduction in blue light reaching the photoreceptors, hence the current interest in the role of lutein in macular disease.

Hammond \& Caruso-Avery (2000) attempted to determine 'average' levels of macular pigment optical density using a heterochromatic flicker photometer. They studied 217 (seventy-nine men, 138 women) US subjects and found the average macular pigment optical density was 0.22 (SD 0.13) milliabsorbance units/d. The average macular pigment optical density tended to decrease with age and was significantly lower in women than men $(13 \% ; P<0.05)$, heavy smokers compared with light $(P<0 \cdot 0045)$ and nonsmokers $(P<0.034)$, and in individuals with light $v$. darkcoloured irises $(18 \% ; P<0.009)$.

Studies investigating supplementation with lutein and $\beta$-carotene suggest that there is an interaction between lutein and $\beta$-carotene when taking $\beta$-carotene supplements $(30 \mathrm{mg} / \mathrm{d})$ over an extended period of time (6 weeks). Reductions in plasma lutein concentrations were observed on ingestion of large doses $(30 \mathrm{mg} / \mathrm{d})$ of purified $\beta$-carotene (Micozzi et al. 1992). In eight subjects (three female, five 
male), Gartner et al. (1996) investigated this interaction further and found a preferential absorption of the xanthophylls lutein and zeaxanthin $v$. $\beta$-carotene. Fourteenfold and fourfold higher lutein and zeaxanthin levels respectively were observed in the chylomicron fraction.

\section{Human blood and milk levels of lutein and zeaxanthin in the neonate}

Lutein concentrations represent about 20-30\% of total blood carotenoids with an average Western diet, while zeaxanthin concentrations represent only about 2-4\%. Concentrations in the blood vary greatly between individuals (Thurnham, 1994). There is little information on blood lutein and zeaxanthin levels in neonates, and no information on whether infant concentrations of these carotenoids or the concentration in the mother's blood have any relationship with visual impairment. It is suggested that lutein and zeaxanthin may diffuse across the placenta in amounts controlled by the concentration in the mother's plasma, since there are direct correlations between the respective amounts of the two carotenoids in the mother's and infant's plasma (Jewell et al. 2000). Fig. 1 shows the correlation between the concentrations of plasma lutein in fifty-four mothers and infants $(r 0.290, P=0.035)$ and Fig. 2 shows the same correlation for zeaxanthin ( $r$ 0.448, $P<0 \cdot 001)$.

Levels of lutein in human milk are reported to be two to three times higher than those of $\beta$-carotene, whereas their concentrations in mother's blood are approximately the same (Khachik et al. 1997). This observation suggests that lutein may be actively secreted into milk rather than passively diffusing as the other carotenoids apparently do. Currently, there is little information on the levels of zeaxanthin in human milk, but preliminary analysis of human milk suggests that concentrations are similar to those of plasma. Human milk is the main source of lutein and zeaxanthin for infants until weaning occurs, as is indicated in some recent work from our laboratory. Fig. 3 gives these results, which show a high correlation between lutein in plasma of the mothers and that in the plasma of breast-fed infants $(n 9, r 0.803, P=0.005)$. If lutein and zeaxanthin are of importance in protecting the RPE of the young infant, this finding supports the view that breast-feeding is the best form of nourishment for the infant, since formula may contain no lutein.

Premature infants, like all low-birth-weight infants, require extra nutrients for rapid growth, but are at a particular nutritional disadvantage because they have missed the period of maximum placental transfer of energy and nutrients during the last weeks of pregnancy. In addition, gastrointestinal and renal functions are immature in the premature infant, potentially resulting in poorer absorption and reduced retention of nutrients.

Premature infants are at a higher risk of visual and neurodevelopmental disorders and it has been suggested that the lack of a supply of long-chain polyunsaturated fatty acids, which is available to the full-term infant via the placenta, may be contributory. There is evidence that premature infants who receive breast milk rather than formula milk have better developmental outcomes (British Nutrition Foundation, 1992).

Breast milk from women who deliver premature infants contains more fat, protein and $\mathrm{Na}$, but less carbohydrate than full-term milk, and its energy value is also greater. There is evidence that this milk supports better growth than mature breast milk (Editorial, 1988). Preterm formulas have a higher nutrient density than standard formulas, and provide energy, protein and $\mathrm{Na}$ in amounts similar to those of premature breast milk. The need to supplement preterm formulas with appropriate amounts of long-chain polyunsaturated fatty acid (arachidonic acid and docosahexaenoic acid) has been acknowledged (Carnielli et al. 1996). The current feeding approach in hospitals is to

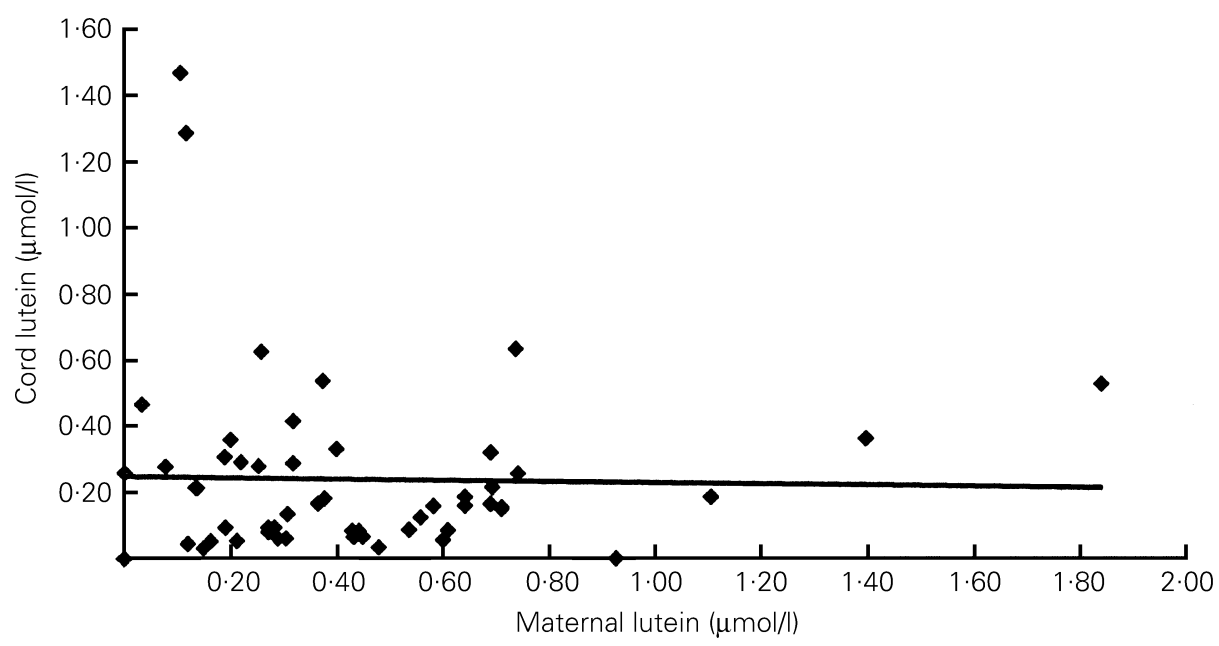

Fig. 1. Lutein concentrations in plasma of Northern Ireland mothers $v$. infants. Fifty-four paired samples of maternal and cord blood were collected immediately after delivery at the Royal Maternity Hospital, Northern Ireland. Measurements of retinol, lutein, $\alpha$ - and $\beta$-carotene, $\alpha$ - and $\beta$-cryptoxanthin, tocopherol and zeaxanthin were obtained for plasma by HPLC, with the plasma extraction method of Thurnham et al. (1988) and HPLC procedure of Emenheiser et al. (1996). $r 0.290, P=0.035$. 


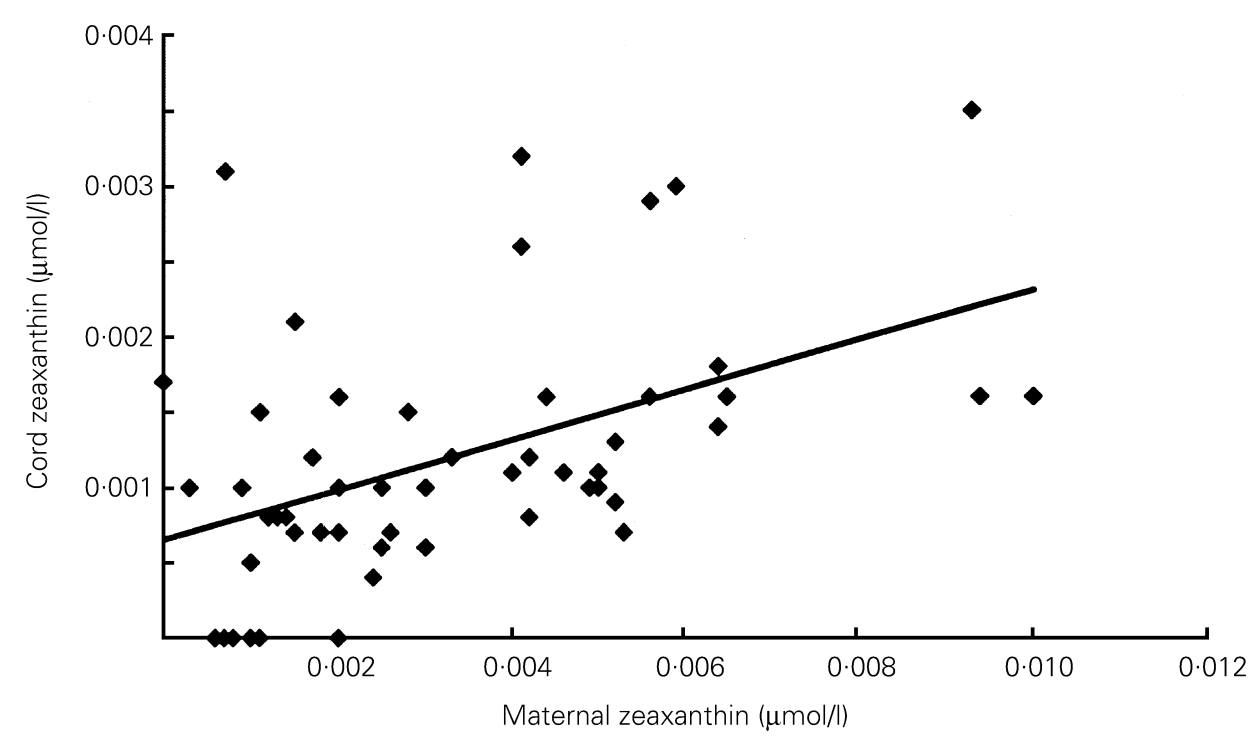

Fig. 2. Zeaxanthin concentrations in plasma of Northern Ireland mothers $v$. infants. Fifty-four paired samples of maternal and cord blood were collected immediately after delivery at the Royal Maternity Hospital, Northern Ireland. Measurements of retinol, lutein, $\alpha$ - and $\beta$-carotene, $\alpha$ - and $\beta$-cryptoxanthin, tocopherol and zeaxanthin were obtained for plasma by HPLC, with the plasma extraction method of Thurnham et al. (1988) and HPLC procedure of Emenheiser et al. (1996). $r 0.448, P<0.001$.

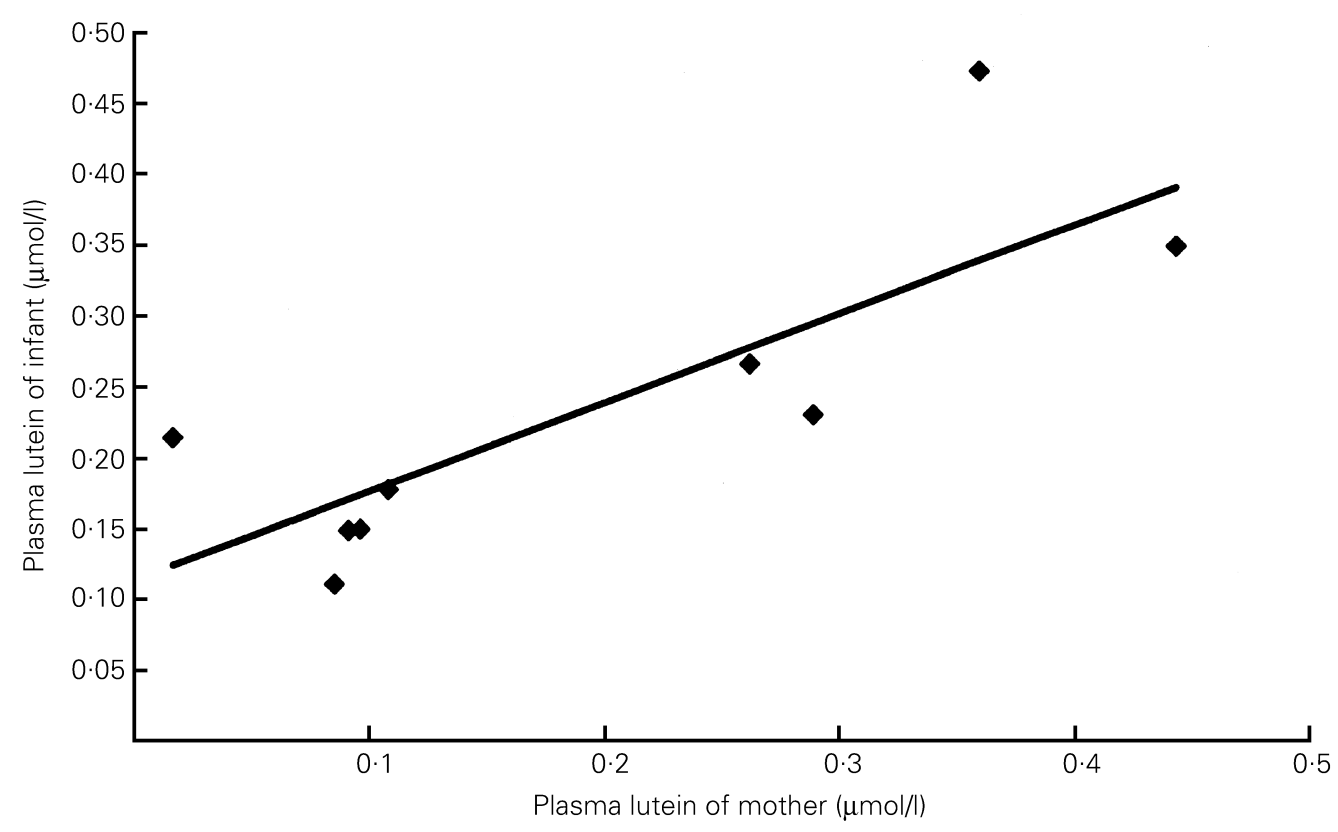

Fig. 3. Plasma lutein concentrations of Nigerian mothers and their breast-fed infants. Nine mothers and their infants, who presented in good health, were recruited from the Eleyele Day Clinic, Ife, Nigeria, West Africa. Measurements of retinol, lutein, $\alpha$ - and $\beta$-cryptoxanthin, tocopherol and zeaxanthin were obtained for plasma and breast-milk samples, where sufficient sample was available. The plasma extraction method was that of Thurnham et al. (1988) and HPLC procedure was that of Emenheiser et al. (1996). $r$ 0.803, $P=0.005$.

give either preterm formula or a combination of breast milk and preterm formula before or up to discharge (Jones \& Spencer, 1999). The findings of Lucas et al. (1997) 'suggests that breast-feeding may promote faster growth in infants compromised by poor growth in utero'.

\section{Absorption and bioavailability of carotenoids in the body}

As yet there is no specific functional biochemical indicator of carotenoid efficiency (other than the provitamin A activity of some carotenoids) or animal model of deficiency. Without a functional marker for biological activity of 
carotenoids in the body, 'bioavailability' has been taken to mean 'assimilation efficiency' or the ability to accumulate carotenoids into a defined body pool (Parker et al. 1999). Such pools may include plasma chylomicrons, adipose tissue or the macular pigment of the eye (Parker et al. 1999). Macular pigment density may be a near functional indicator of the bioavailability of lutein and zeaxanthin, since these carotenoids may be implicated in macular function and prevention of degeneration (Bone et al. 1988; Parker et al. 1999). Macular pigment density can be measured noninvasively to assess its relationship with carotenoid intake, as discussed earlier (Hammond et al. 1997; Landrum et al. 1999).

Absorption of carotenoids from different foods is influenced by a variety of lifestyle factors, and so correlation coefficients between habitual intake and blood concentrations are usually low (Thurnham \& NorthropClewes, 1999). Plasma carotenoid levels respond very quickly to changes in dietary intake, and the circulating concentration is directly related to the amount in the diet (Willett et al. 1983; Micozzi et al. 1992).

Bioavailability of carotenoids in human subjects is difficult to assess, but may be attempted by two methods; by assessing absorption efficiency using chylomicrons or by measuring plasma carotenoid concentrations. There have been a number of absorption studies, and reported estimates of absorption efficiency have ranged from 1 to $99 \%$ (van Vliet et al. 1995; Gartner et al. 1996; O'Neill \& Thurnham 1998). Vegetables are generally a poor source of carotenoids, and perhaps more importantly, consumption of foods rich in carotenoids is low in those groups who have a higher proportion of LBW infants.

\section{Conclusions}

Premature birth is the leading cause of neonatal mortality, morbidity and long-term disability, and premature infants are at a high risk of visual impairment. There have been considerable improvements in treatment in the last two decades, but long-term morbidity is still a problem. Oxidant stress has been implicated in the aetiology of these conditions, as with age-related disorders, and therefore antioxidants may be protective. Attempting to maintain the balance between reactive oxygen species and antioxidants by dietary means may help prevent or minimise the onset of oxidant-related disorders.

Lutein and zeaxanthin may be protective against the pro-oxidant effects of light by absorbing blue light and quenching singlet oxygen and free radicals. Lutein supplementation increases macular pigment optical density, and hence decreases the amount of blue light reaching the photoreceptors.

The macular pigments are of dietary origin, and consumption of those few foods rich in bioavailable carotenoids is low in those groups who have a high proportion of LBW infants.

The plasma concentrations of carotenoids in mothers and infants tend to be correlated. It is thought that lutein and zeaxanthin diffuse across the placenta in amounts controlled by the concentration in the mother's plasma, since there are direct correlations between the respective amounts in the plasma of mothers and infants. Presently, there is little information on the levels of zeaxanthin in human milk, but preliminary analyses suggest that concentrations are similar to those in plasma. There is also a high correlation between lutein concentrations in the plasma of mothers and their breast-fed infants.

The mechanism of uptake and stabilisation of lutein and zeaxanthin into the eye is still not known. Tubulin, recently identified as the major carotenoid-binding protein, may play a role in the physiology of the macula.

\section{References}

Alberman E \& Botting B (1991) Trends in prevalence and survival of very low birthweight infants, England and Wales: 1983-7. Archives of Disease in Childhood 66, 1304-1308.

Audit Commission (1993) Children First: A Study of Hospital Services. London: H.M. Stationery Office.

Bernstein PS, Balashov NA, Tsong ED \& Rando RR (1997) Retinal tubulin binds macular carotenoids. Investigative Ophthalmology and Visual Science 38, 167-175.

Blanche D, Gesquiere L, Loreau N \& Durard P (1999) Oxidant stress: the role of nutrients in cell-lipoprotein interactions. Proceedings of the Nutrition Society 58, 559-563.

Bohin S, Draper ES \& Field DJ (1999) Health status of a population of infants born before 26 weeks gestation derived from routine data collected between 21 and 27 months post-delivery. Early Human Development 55, 9-18.

Bone RA, Landrum JT, Fernandez L \& Tarsis SL (1988) Analysis of the macular pigment by HPLC: Retinal distribution and age study. Investigative Ophthalmology and Visual Science 34, 2033-2040.

Bone RA, Landrum JT, Friedes LM, Gomez CM, Kilburn MD, Menendez E, Vidal I \& Wang W (1997) Distribution of lutein and zeaxanthin stereoisomers in the human retina. Experimental Eye Research 64, 211-218.

Bone RA, Landrum JT \& Tarsis SL (1985) Preliminary identification of the human macular pigment. Vision Research 25, 1531-1535.

British Nutrition Foundation (1992) Unsaturated Fatty Acids: Nutritional and Physiological Significance. London: Chapman Hall.

Bonn D (1998) Keeping the stork at bay until the time is right. Lancet 351, 576.

Carnielli VP, Pederzini F, Vittorangeli R, Luijendijk IHT, Boomaars WEM, Pedrotti D \& Sauer PJJ (1996) Plasma and red blood cell fatty acids of very low birth weight infants fed exclusively with expressed preterm human milk. Pediatric Research 39, 671-679.

Cartlidge PHT, Jones HP, Stewart JH, Drayton MR, Ferguson DS, Matthes JWA, Minchom PE \& Moorcraft J (1999) Confidential enquiry into deaths due to prematurity. Acta Paediatrica $\mathbf{8 8}$, 220-223.

Cooke RW (1996) Improved outcome for infants at the limit of viability. European Journal of Pediatrics 155, 665-667.

Doyle LW, Rogerson S, Chuang S, James M, Bowman ED \& Davis PG (1999) Why do preterm infants die in the 1990s? Medical Journal of Australia 170, 528-532.

Editorial (1988) Breast not necessarily best. Lancet i, 624-626.

Elder DE, Hagan R, Evans SF, Benninger HR \& French NP (1999) Hospital admissions in the first year of life in very preterm infants. Journal of Paediatrics and Child Health 35, 145-150.

Emenheiser C, Simunovic W, Sander LC \& Schwartz SJ (1996) Separation of geometrical carotenoid isomers in biological extracts using a polymeric C30 column in reversed-phase liquid 
chromatography. Journal of Agricultural and Food Chemistry 44, 3887-3893.

Ford ES, Will JC, Bowman BA \& Venkat Narayan KM (1999) Diabetes mellitus and serum carotenoids: Findings from the Third National Health and Nutrition Examination Survey. American Journal of Epidemiology 149, 168-176.

Gartner C, Stahl W \& Sies H (1996) Preferential increase in chylomicron levels of the xanthophylls lutein and zeaxanthin compared to $\beta$-carotene in the human. International Journal of Vitamin and Nutrition Research 66, 119-125.

Gibson A (1982) Prematurity. In Fetal and Neonatal Pathology [A Barson, editor]. London: Praeger Scientific.

Gorman WA, Fallon M, Kelly M, Clarke T, Griffin E, Matthews T, Murphy J, O'Brien N \& Sheridan M (1996) The Dublin outcome for low birth-weight infants. Irish Medical Journal 89, 186-187.

Halliwell B \& Aruoma OI (1991) DNA damage by oxygen-derived species: Its mechanisms and measurement in mammalian systems FEBS Letters 281, 9-19.

Hammond BR \& Caruso-Avery M (2000) Macular pigment optical density in a southwestern sample. Investigative Ophthalmology and Visual Science 41, 1492-1497.

Hammond BR, Johnson EJ, Russell RM, Krinsky NF, Yeum KJ, Edwards K \& Snodderly DM (1997) Dietary modification of human macular pigment density. Investigative Ophthalmology and Visual Science 38, 1795-1802.

Hughes DA (1999) Effects of dietary antioxidants on the immune function of middle-aged adults. Proceedings of the Nutrition Society 58, 79-84.

Jacques PF, Taylor A, Hankinson SE, Willett WC, Mahnken B, Lee Y, Vaid K \& Lahav M (1997) Long-term vitamin C supplement use and prevalence of early age-related lens opacities. American Journal of Clinical Nutrition 66, 911-916.

Jewell VC, Sweet D, Tubman R, Northrop-Clewes CA \& Thurnham DI (2000) Lutein and zeaxanthin levels in newborn infants and their mothers. Proceedings of the Nutrition Society 59, 47A.

Jones L \& Spencer A (1999) Successful preterm breastfeeding. Practising Midwife 12, 54-57.

Khachik F, Spangler CJ \& Cecil Smith J (1997) Identification, quantitation, and relative concentrations of carotenoids and their metabolites in human milk and serum. Analytical Chemistry 69, 1873-1881.

Landrum JT, Bone RA, Joa H, Kilburn MD, Moore LL \& Sprague KE (1997) A one year study of the macular pigment: the effect of 140 days of a lutein supplement. Experimental Eye Research $\mathbf{6 5}$, 57-62.

Landrum JT, Bone RA, Moore LL \& Gomez CM (1999) Analysis of zeaxanthin distribution within individual human retinas. Methods in Enzymology 299, 457-467.

Le Blanc MH, Graves GR, Rawson TW \& Moffitt JM (1999) Longterm outcome of infants at the margin of viability. Journal of the Mississippi State Medical Association 40, 111-114.

Lucas A, Fentrell MS \& Davies PW (1997) Breastfeeding and catch-up growth in infants born small for gestational age. Acta Paediatrica 86, 564-569.

Main DM \& Hadley CB (1988) The role of ultrasound in the management of preterm labor. Clinical Obstetrics and Gynecology 31, 53-60.

Malinow MR, Feeney-Burns L, Peterson LH, Klein ML \& Neuringer M (1980) Diet-related macular anomalies in monkeys. Investigative Ophthalmology and Visual Science 19, 857-863.

Micozzi MS, Brown ED, Edwards BK, Bieri JG, Taylor PR, Khachik F, Beecher GR \& Smith JC (1992) Plasma carotenoid response to chronic intake of selected foods and $\beta$-carotene supplements in men. American Journal of Clinical Nutrition $\mathbf{5 5}$, 1120-1125.

Minicucci G, Lepore D \& Molle F (1999) Abnormal retinal vascularisation in preterm children. Lancet 353, 1099.

Morris BA, Miller-Loncar CL, Landry SH, Smith KE, Swank PR \& Denson SE (1999) Feeding, medical factors and developmental outcome in premature infants. Clinical Pediatrics 38, 451-457.

National Perinatal Epidemiology Unit (1994) Disability and Perinatal Care: Measurement at 2 Years. A Report of 2 Working Groups Convened by the National Perinatal Epidemiology Unit and Oxford Regional Health Authority. Oxford: NPEU.

O'Neill E \& Thurnham DI (1998) Intestinal absorption of $\beta$-carotene, lycopene and lutein in men and women following a standard meal: response curves in the triacylglycerol-rich lipoprotein fraction. British Journal of Nutrition 79, 149-159.

Parker RS, Swanson JE, You C, Edwards AJ \& Huang T (1999) Bioavailability of carotenoids in human subjects. Proceedings of the Nutrition Society 58, 155-162.

Pennefather PM, Clarke MP, Strong NP, Cottrell DG, Dutton J \& Tin W (1999) Risk factors for strabismus in children born before 32 weeks gestation. British Journal of Ophthalmology 83, 514518.

Sommerburg O, Keunen JEE, Bird AC \& Kuijk FJGM (1998) Fruits and vegetables that are good sources for lutein and zeaxanthin: the macular pigment in human eyes. British Journal of Ophthalmology 82, 907-910.

Sommerburg O, Siems WG, Hurst JS, Lewis JW, Klinger DS \& van Kuijk FJGM (1999) Lutein and zeaxanthin are associated with photoreceptors in the human retina. Current Eye Research 19, 491-495.

Thurnham DI (1988) Vitamin C (ascorbic acid): antioxidant functions of vitamin $\mathrm{C}$ in disease in man and animals. Comparative Nutrition 34, 91-103.

Thurnham DI (1994) Carotenoids: functions and fallacies. Proceedings of the Nutrition Society 53, 77-87.

Thurnham DI \& Northrop-Clewes CA (1999) Optimal nutrition: vitamin A and the carotenoids. Proceedings of the Nutrition Society 58, 449-457.

Thurnham DI, Smith E \& Flora PS (1988) Concurrent liquidchromatographic assay of retinol, alpha-tocopherol, betacarotene, alpha-carotene, lycopene, and beta-cryptoxanthin in plasma, with tocopherol acetate as internal standard. Clinical Chemistry 34, 377-381.

Willett WC, Stampfer MJ, Underwood BA, Taylor JO \& Hennekens CH (1983) Vitamins A, E and carotene: effects of supplementation on their plasma levels. American Journal of Clinical Nutrition 38, 559-566.

World Health Organization (1961) Public Health Aspects of Low Birth Weight - Third Report of the Expert Committee on Maternal and Child Health. Technical Report Series no. 217. Geneva: WHO.

Van Vliet J, Schreurs WHP \& van der Berg H (1995) Intestinal $\beta$-carotene absorption and cleavage in men: response of $\beta$-carotene and retinyl esters in the triacylglycerol-rich lipoprotein fraction after a single dose of $\beta$-carotene. American Journal of Clinical Nutrition 62, 110-116.

Veen S, Ens Dokkum MH, Schreuder AM, Verloove Vanhorick SP, Brand R \& Ruys JH (1991) Impairments, disabilities, and handicaps of very preterm and very-low-birthweight infants at five years of age. The Collaborative Project on Preterm and Small for Gestational Age Infants (POPS) in The Netherlands. Lancet 338, 33-36.

Yu VYH, Wong PY, Bajuk B, Orgill AA \& Astbury J (1986) Outcome of extremely low birth weight infants. British Journal of Obstetrics and Gynaecology 93, 162-170. 